\title{
Demarcating presentism
}

\author{
Christian Wüthrich*
}

\begin{abstract}
This paper argues that recent arguments to the effect that the debate between presentism and eternalism lacks any metaphysical substance ultimately fail, although important lessons can be gleaned from them in how to formulate a non-vacuous version of presentism. It suggests that presentism can best be characterized in the context of spacetime theories. The resulting position is an ersatzist version of presentism that admits merely non-present entities as abstracta deprived of physical existence. Ersatzist presentism both escapes the charges of triviality and promises to offer a route to solving the grounding problem which befalls its more traditional cousins.
\end{abstract}

\section{Introduction: presentism and its motivations}

Presentism accords an ontologically central role to the present, at the existential expense of past and future entities. It thereby asserts, with some intuitive appeal, that there remains a fundamental difference between time and space: while we all happily concede that other spatial locations, such as New York or Paris, exist and are equally real as Las Vegas (or Amsterdam, whichever is "here"), presentists deny that temporal instances other than the present moment exist. Presentism derives its appeal, first and foremost, from our intuition that past things have existed, but no longer do, and that future events have yet to occur. Though ultimately controversial, presentists have urged that their view is better placed than its rivals to account for our sense that the future is open, that time passes, and that events irretrievably slip away from us. It is designed, in the first instance, to capture salient features of our experience of temporality.

Eternalists, on the other hand, affirm that past and future entities exist on a par with present ones. As far as their ontological status is concerned, eternalism admits all events to the same lofty level, quite regardless of the time at which they occur. It thus certainly appears as if presentists and eternalists are engaged in a substantive metaphysical debate. Recently, however, several authors, including Callender (2000), Dorato (2006), Meyer (2005), and Savitt (2006), have claimed that this appearance is deceptive. They argue that presentism either collapses into a doctrine that is trivially true or trivially false, or else is equivalent to eternalism. The first purpose of this paper, addressed in Section ??, is to illustrate how these trivialization arguments fail. Once we recognize that the debate concerns physical existence rather than our language used to express existence claims, and once we do full justice to what the presentist wants to claim concerning existence, the substance of the debate can be recovered. The second objective, to be pursued in Section ??, will then be to at least make the first steps toward a demarcation of a non-trivial presentist position

*I am indebted to Craig Callender, Jonathan Cohen, Greg Frost-Arnold, Nat Jacobs, Thomas Müller, Tomasz Placek, Steve Savitt, and James Woodbridge for discussions and comments and to audiences at Geneva, the University of Nevada, Las Vegas, the BSPS meeting in Norwich, and the EPSA meeting in Amsterdam. This project has been funded in part by the Swiss National Science Foundation ("Properties and Relations", 100011-113688), by the University of California, San Diego, and by the Hellman Family Foundation. 
that is substantively distinct from eternalism. In Section ??, I will conclude by showing how the two metaphysics do not merely offer different, but compatible, perspectives, pace Savitt.

\section{Trivialization arguments debunked}

The sum total of physical existence, according to the presentist, can be organized in a threedimensional manifold. In contrast, eternalists consider the full four-dimensional "block universe" as the sum total of existence. Despite this seemingly straightforward sense in which we have a substantive ontological debate here, there has been a recent spate of published worries concerning the well-formedness of the debate. For instance, Callender (2000) finds it "surprisingly difficult to understand what presentism amounts to exactly" (S588). Furthermore, he asserts that it is "not obvious that the two views differ over much" (ibid.). Taken as such, I can wholeheartedly agree with this sentiment. But if his argument is supposed to achieve more than the expression of a surprising difficulty, I bid adieu.

Callender imagines that spacetime events carry lightbulbs which are "on" if the corresponding event exists, and "off" if it doesn't and then proposes a "refrigerator analogy": the debate that two people might have in front of a closed refrigerator about whether the light inside is on or off is suggested to be analogous to the issue of whether non-present events exist. But, as Callender warns, the analogy is limited as in the former case, but not the latter, there is an agreement that there is a bulb in the refrigerator. As far as the presentist is concerned, if a bulb is off, then it doesn't exist. Thus, for him, only bulbs that are on exist - which is precisely what the eternalist claims. Callender thus wonders what the debate might be about, since everybody agrees that all the bulbs there are are on.

This argument fails if it is intended to be a trivialization argument as characterized above. Even if there is universal concurrence that all and only lighted bulbs exist, there is plenty of room for disagreement, if we accept that there exists a proper subset relation between the set of the lighted bulbs of the presentist and the corresponding eternalist set 11 If this is the case, then their ontologies, whatever they consist of, even if they range over the same type of entities and carve out existing objects in the same way, cannot be identical. But if their ontologies are inequivalent, then the positions are substantively distinct and at most one of them can be true of the actual world. All of this is admittedly still rough, but so was the analogy.

Let me turn to the more or less standard trivialization argument as it has recently been discussed in the literature. I will use Savitt's (2006) particular formulation to this end ${ }^{2}$ Savitt raises similar worries as Callender. In particular, he thinks that disambiguating the temporal equivocation that is inherent in "is" or "exists" will invariably lead to a deflation of the opposition between presentism and eternalism. Regardless of whether we interpret "exists" tenselessly, tensedly, DETENSEDLY (either is, was, or will be) etc., existence statements will either come out as trivially true or trivially false such that there cannot be any reasonable disagreement between the camps. The heart of the problem, says Savitt, is that we cannot make sense of unrestricted quantification without the specification of a contrast class beyond the empty "non-existent." Once we have a specification of such a contrast class, and thus a well-defined quantification and a disambiguated sense of existence, the distinction between presentism and eternalism evaporates, because there exists no existence claim about which presentists and eternalists can reasonably disagree. For instance, you

\footnotetext{
${ }^{1}$ Assuming, of course, that there exist sets of events.

${ }^{2}$ Similar versions of essentially the same argument can be found in Crisp (2004), Dorato (2006), Hestevold and Carter (2002), Lombard (1999), Meyer (2005), although it should be noted that Crisp and Hestevold and Carter reject trivialization.
} 
exist as opposed to Caesar because he once existed (tensed) but does not now; Caesar exists as opposed to Santa Claus because he EXISTS (detensed) but Santa Claus is fictitious (don't tell my daughters). Savitt considers, and rejects, different attempts to reinstate a substantive distinction that rely on the use of quantifiers or tense operators. The problem, according to Savitt is that every potential distinction reduces to a formula like "All and only those objects that exist exist" to which both sides trivially agree. Without going into the detailed machinery of each approach, let me illustrate on one example how trivialization arguments as put forth by Savitt go awry.

This example is based on Lewis's (1986) suggestion of how to understand unrestricted quantification in terms of what he calls "existence simpliciter." Hestevold and Carter (2002) use Lewis's notion to propose as supposedly non-trivial brand of presentism the position which asserts that

(1) Necessarily, if $x$ exists simpliciter, then $x$ presently exists.

Savitt dismisses their attempt by arguing that if we follow Lewis in interpreting "exists simplicter" as ranging over everything in all possible worlds then (1) is equivalent to

(2) Necessarily, if $x$ presently exists or $x$ did exist or $x$ will exist or $x$ possibly exists, then $x$ presently exists.

But this, he claims, is trivially false. Since the presentist should not be characterized as someone who is committed to a trivially false claim, Savitt concludes, existence simplicter doesn't help in defining the position. He then goes on the argue that similar concerns can be raised against attempts to tensed operators instead of quantifiers.

The problem, however, with Savitt's dismissal of characterizing the debate in terms of existence simpliciter is that it rests on an invalid argument: the presentist interprets existence simpliciter in (1) to have narrow range such as to exclude anything that is non-present, yet (2) will only come out as false if the quantification ranges over at least something that is non-present. But it is of course a necessary condition for an inference to be valid that the range be fixed. Even though Savitt seems to think that if the net of the quantifier is cast maximally wide, i.e. if quantification is unrestricted, then Caesar's crossing of the Rubicon must be caught in it. But there is no reason, as Crisp (2004) rightly notes, that the presentist has to assent to that.

So let's keep the range fixed and thus validate the inference from (1) to (2). Naturally, the presentist will want to keep the range narrower than the eternalist, in accordance with her ontological commitments. When we keep the range tightly presentist, however, it is mistaken to interpret (2) as trivially false, as Savitt does. Instead, it becomes non-trivially true. Thus, what allows us to validly infer (2) from (1) is a hidden, but substantive metaphysical assumption that must be taken into account when evaluating the truth values of the relevant sentences.

In a similar vein, Dorato (2006) argues that the debate is pragmatic at best. Debating over whether some future event "is real" or not, as he takes the presentist and the eternalist to do, he laments the impossibility of making this precise in the absence of a contrast class to "reality." Given the failure to procure a viable contrast class, he insists, the ontic status of events remains otiose. But reminding ourselves that this is supposed to be a debate about what physically exists, what could be more fundamental than physical existence? Giving a list, or an account, of what physically exists surely is possible without also providing a "contrast class." But even if we accept the requirement to produce a contrast class, it is unclear what could keep us, in principle, from starting to list entities which do not physically exist. What this entails, as Dorato rightly notes, is that we cannot reasonably ask the presentists to list events they insist do not exist and, once they comply, strike them with an ontological commitment to those events. What this further means is that we need to come up with a way of representing events in our language in a way that is not 
tied to ontological commitments. This is exactly what the ersatzist presentist presented in Section ?? will try to achieve $3^{3}$

Parts of Dorato's sceptical case are based on what I take to be complaints concerning the difficulty of formulating a coherent notion of passage or becoming. Since I believe that becoming can be dissociated from presentism, which is purely a claim concerning existence, I am not moved by these complaints, as justified as they may be. The sceptic may insist that the presentist, in her necessary effort to accommodate into her theory that some events have been the case and others will be the case, must invariably admit more into her theory than merely the present, for otherwise these other, non-present presents and what obtains at them are not modeled. This objection can be understood in two ways. First, as a demand for animation, i.e. for the "Heraclitean" version of presentism which assumes a dynamic succession of presents, or that change is a fundamental aspect of reality, at the expense of its "Parmenidean" cousin which denies such commitments. But if that's the worry, then it is simply misplaced qua objection to the substantiality of the debate. As I have argued elsewhere (forthcoming), passage is not a necessary part of a presentist theory. Presentism is only an ontological claim concerning existence, not one about any further properties of that which exists (over and above that it is present). If you look for animation, look elsewhere. It may well be the case that any attempt to accommodate animation will be frustrated either by triviality or by incoherence. I certainly don't pretend to offer such a theory. Second, if the request is for some resources to be able to represent non-present events in a presentist framework, I agree but insist that such representation not be fraught with the ontic baggage of physical existence, in keeping with the presentist spirit. The version of presentism presented in Section ?? tries to fit exactly that bill.

Much of philosophy of time has been riddled with an unfortunate infatuation with language for the last one hundred years. It is the sceptics' merit to expose as unsuccessful attempts to reify mere linguistic or logical tools such as tensed operators into substantive metaphysical differences $4^{4}$ Ironically, at least some of the trivialization arguments fall in the same linguistic trap when they infer from a difficulty to disambiguate metaphysical positions in ordinary English, enhanced by tensed operators or the like, to a conclusion that there is no metaphysically substantive issue to be had.

My diagnosis thus partly differs from the one offered by Callender (n.d.). Callender both identifies an unhealthy obsession with language and with existence in the philosophy of time and sets out to combat the latter. Vanquishing this obsession, he recommends, is achieved in three simple steps: first, cast doubt on the metaphysical substance of the debate between presentism and eternalism; second, deny that the positions are empirically distinct; and third, show that the differences between them, should they exist, are unable to explain either the vividness of the present vis-à-vis the past or the future, or the experience of temporal passage, or other such phenomena. While everything I say in this essay is compatible with the second and third steps recommended as therapy to cure philosophy of time's obsession with existence, I resist trivializing the debate between the positions at stake. While I concur that naked existence by itself may well be explanatorily impotent, it forms the basis on which a theoretical building of great explanatory and descriptive potency can be erected. So let's start building.

\footnotetext{
${ }^{3}$ And so does Russell's theory of definite descriptions, as Jonathan Cohen reminded me.

${ }^{4}$ Incidentally, it is not obvious that the triviality charge sticks. As Sider (2006) argues, if the debate were merely verbal, then there ought to be a translation function from the set of all sentences accepted by the presentist to the set of those accepted by the eternalist such that, at a minimum, the translation function preserves truth values and inferential relations. Sider goes on to argue that at least for some obvious candidate translation functions, this necessary condition is not met. He concludes that the sceptic has not yet shown the debate to be trivial and must accept the argumentative onus to produce a translation function which exposes the emptiness of the debate.
} 


\section{Ersatzist presentism}

Let us move on to the positive contribution of this essay. Towards the end of last section, we recognized that some way or other to represent events must be found that is independent of whether or not we take the represented events to form part of the sum total of physical existence. The fate of the triviality charges rests on the delicacies of representation without ontological taxation. Arguably, this is not a problem for an eternalist as she must not tread so carefully as to avoid ontological commitments to past or future events. But it is the core of the challenge issued to the presentist. By the same token, such a non-ontic representation must be given in order to fully express the substance of the metaphysical debate. Without it, eternalism would become the uncontested game in town 5 Thus, in order to avoid equivocations of the type used by Savitt to undermine the debate, let us set the positions up in a language that is not so prone to them.

Like (Callender and) Savitt, I believe that the distinction at stake is clearest in the context of spacetime theories, presupposing a four-dimensional manifold $\mathcal{M}$ with certain topological and differential structure. Such a formulation should ideally be neutral among distinct spacetime theories and thus among different particular spacetime structures. In this view, the two metaphysics of time are taken to disagree as to over which sets of events or spacetime points they quantify, cum ontological commitment qua physical existents, or as to at which spatiotemporal locations existing entities can be.

In this set-up, eternalism can be understood as the position awarding existence to all events in $\mathcal{M}$, with the spatio-temporal properties given by the relations among the events as they are encoded in the metric field $g_{a b}$ defined on $\mathcal{M}$. Presentism, on the other hand, takes an equivalence relation $S$ which foliates $\mathcal{M}$ ("simultaneity") and then restricts physical existence to those events in the folium corresponding to "now" 6 Time, for the presentist, then is the one-dimensional linearly ordered quotient set induced by $S$. As can be directly seen from these formulations, presentism and eternalism have a substantive disagreement. Their respective sets of existing spacetime events are simply non-identical in that the presentist's is a proper subset of the eternalist's. Furthermore, presentism requires a well-defined equivalence relation, but eternalism does not.

One might object to this characterization on the basis that it does not seem to do justice to presentism since it presupposes the construction of a four-dimensional manifold from which most every point is then substracted. Also, it can be argued that the troubles that the presentist then faces with the relativity of simultaneity can ultimately be traced back to this, for the presentist unnatural, construction. It seems as if defining presentism in this fashion amounts to cheating in a way that betrays the core of presentist beliefs. But it can hardly be contested that it is perfectly reasonable to ask presentism to characterize, or describe, what is the sum total of physical existence according to it. Just as in the debate on whether possible worlds should be reified, one can then insist that there is a position to be had in the temporal case analogous to ersatzism about possible worlds. Such an ersatzist presentism would admit merely non-present events only as abstract entities that lack any physical existence, introduced solely for representational purposes. These non-present ersatz events do not form part of the sum total of physical existence. Ersatzist presentism is a form of presentism - it asserts that everything that exists physically is present even though there are abstract existents located at non-present times. 7

\footnotetext{
${ }^{5}$ Apart, perhaps, from the growing block view. But presumably, the growing blocker must find an ontologically uncharged way of referring to future events to set herself apart from the eternalist.

${ }^{6}$ It should be noted that there may be alternative ways of constructing the set of events that physically exist according to the presentist, in particular in response to the Rietdijk-Putnam argument; cf. Wüthrich (forthcoming).

${ }^{7}$ Alternatively, as was suggested to me by James Woodbridge, a presentist could think of non-present events not just as non-physical abstracta, but as entirely fictional enities. While being at least prima facie workable, such a
} 
It would be wrong to think that ersatzist presentism is a lesser cousin of a more genuine, or a more thoroughgoing presentism - it is not a mere ersatz for presentism. First, it naturally permits the metaphysician with presentist inclinations to formulate her theory without falling prey to charges of trivialization of the form discussed above. Secondly, and more speculatively, it may form a basis on which the presentist can solve her grounding problem, i.e. it may offer a presentist route to truthmakers, or at least ersatz truthmakers, for statements about non-present events. More would need to be said about how exactly abstract, non-present events relate to concrete, present ones in order to solve the grounding problem, and this gap may nourish worries analogous to those raised against modal ersatzism, but we have at least the beginning of an answer to this challenge at hand with all the mathematical apparatus (and perhaps the resources of a physical spacetime theory) available to characterize the relationship between present and non-present events. It is only the beginning though, as this story must be supplemented by a philosophical account of how the abstracta relate to the physically existing events.

That more work is needed also becomes evident in the face of the likely sceptic objection that the presentist somehow needs the sum of all presents, including those, as it were, not present, in order to make sense of events that have transpired or will transpire. The sceptic might retort that ersatzist presentism with concrete present events and abstract non-present ones is just a re-description of the eternalist ontology under a different vocabulary. After all, what does the difference between abstract and physical existence really amount to? To repeat, I accept that the presentist must say more about how abstractly and physically existing events relate to one another and by virtue of what they belong to one class rather than the other. But if the sceptic's case degenerates into a refusal to accept a distinction between abstract and physical existence, then his usefulness is exhausted beyond his commendable exposure of unkosher reifications of merely linguistic differences 8

\section{By way of conclusion: merely different perspectives?}

With a viable demarcation at hand, one might now proceed to taking a stance and defending it. But in keeping with his sceptical view of the debate, Savitt (2006) thinks this would be a mistake. He argues that even with the full regalia of spacetime theories and their expressive powers in place, presentism and eternalism merely offer different, and certainly not exclusive, perspectives on the same reality. On his understanding, eternalism offers an atemporal perspective from outside of time which does not distinguish among past, present, and future. Presentism, on the other hand, ventures out from "the fact that we are immersed in time" (2006, 124). It seeks no absolute viewpoint, but rather attempts to approach our standing in the world "from within." Following the usual terminology in the study of spatial cognition, the eternalist thus offers an allocentric perspective, while the presentist favours an egocentric (or idiocentric) perspective. Allocentric and egocentric denote two different "frames of reference," or representations in human spatial cognition or animal navigation. In the latter, locations and spatial relations are represented with

fictionalist version of presentism would, I suspect, find it harder to address the grounding problem.

${ }^{8}$ While on tour with this paper, Craig Bourne has kindly drawn my attention to his (2006) version of what he dubs "ersatzer presentism." Relevantly, Bourne develops his version of presentism primarily as a response to the grounding problem, which he believes is the only form of presentism up to the challenge. According to ersatzer presentism, concrete physical existence extends only to present entities-hence presentism. There are, however, non-present times and events. Honouring his presentist commitment, these times and events do not afford physical existence; instead, they are abstracta. Specifically, they are maximally consistent sets of those present-tense propositions we would accept as being true at the time in question. As Bourne insists (2006, 66), rightly in my view, since it takes the constituents of non-present times to be not spatio-temporally or causally related concrete objects but abstract entities, ersatzer presentism evades the triviality objection and can be seen as a distinct and substantive competitor to eternalism. 
respect to the particular perspective of the perceiver, whereas in the former, such representation is independent of the perceiver's position and the "reference direction" is external to the subject (cf. Klatzky 1998). Savitt makes the case for an ecumenical stance that reconciles the two viewpoints. Each perspective, he maintains, "is compelling, unless it errs by thinking that it is the only point of view worth taking" (ibid.). Such a reconciliatory approach, he proposes, could be viewed as forming part of a larger agenda whose goal it is to fuse the Sellarsian "manifest" and "scientific" images of the world "into one truly textured image, as one fuses two similar but distinct images into an image with depth in a stereoscopic viewer" (ibid.). The images reflect, for Savitt, two perspectives on the very same reality. Savitt takes this reconstruction of the debate to lead to a hybrid theory which he thinks may just be what is needed in the philosophy of time.

But if the debate between eternalism and presentism is, as I have argued above, metaphysically substantive in that the two positions are not reducible one to the other, then Savitt's reconciliatory stance must fail. Furthermore, there is no reason why the manifest and the scientific image of the world ought to be regarded as being on a par as far as their claims to faithful representations of the world are concerned. I am not going to argue for a naturalistic methodology here, but merely wish to submit my considered conviction that we have good reason to believe that the scientific image - as fallible as its tenets are - offers the superior epistemic access to the world we inhabit. This in no way implies that the scientific image, being the more fundamental of the two, can eschew the explanatory task of coming to grips with our being-in-the-world, and, in particular, with the phenomenology of temporality which impresses so many philosophers of time. At the end of the day, a complete scientific account will have to explain our experiences as of change and as of transience.

As I have argued elsewhere (forthcoming), a presentist metaphysics is hard pressed to accommodate well established empirical facts such as the relativity of simultaneity and the concomitant Lorentz invariance that are held to obtain worldwide 9 All attempts to salvage presentism in the face of these facts, while logically possible, leave us with a theory that is either not attractive or not presentist in spirit anymore. In a nutshell, the basic problem for (almost) all forms of presentism is that they require a metaphysically robust, objectively valid notion of a spatially extended present, and it seems that that can't be had. A spatially extended present consists of the set of all spacetime points which are simultaneous with the here-now. I take it that in order for a spacetime to permit a robust, objectively valid present with non-trivial spatial extension, it must admit a total ordering relation on the set $\mathcal{M}$ of all spacetime points that distinguishes for all points which other points lie in its past, its future, or are co-present. But special relativity has taught us that such an ordering can at best be partial - there are plenty of pairs of points that simply fail to exemplify an objective, i.e. frame-independent, earlier-than or simultaneous-with relation. I am not suggesting that the presentist cannot possibly meet this challenge. But all the different options available to the presentist, such as the acceptance of a fragmentation of reality or of spatiotemporal solipsism, strike me as rendering the resulting position rather unattractive.

Why is our immersion in space, captured by a spatially egocentric perspective, so easily supplanted by a spatially allocentric view as ontologically more fundamental, but not our temporally egocentric perspective? This question is all the more pressing since a temporally allocentric view seems exactly what is taken by fundamental physics. In the light of the fact that many of our intuitions are demonstrably false, I have recommended an acceptance of the epistemic precedence of the scientific image over the manifest one. Having said that, however, I also accept the explanatory debt owed by the scientific image concerning the phenomenology of temporality. The egocentric perspective, mistakenly celebrated as equipollent by Savitt, assumes a crucial role in a repayment of this debt, since our situatedness in our spatiotemporal home will be an ineliminable feature of any

\footnotetext{
${ }^{9}$ Recent challenges to its universal sway notwithstanding, no violations of Lorentz invariance are known.
} 
such explanation, just as our neurological make-up together, perhaps, with other sorts of facts that are, however, not ontologically basic. But this is a task different from formulating a metaphysical theory of time and shall happily be left for another day. As far as ontological matters are concerned, it is the theoretician's allocentric perspective that matters, while the egocentric viewpoint is secondary, and hence derivative.

\section{References}

Bourne, Craig, A Future for Presentism, Oxford: Clarendon Press (2006).

Callender, Craig, "Shedding light on time", Philosophy of Science 67 (2000): S587-S599.

Callender, Craig, "Time's ontic voltage", manuscript (n.d.).

Crisp, Thomas M, "On presentism and triviality", Oxford Studies in Metaphysics 1 (2004): 15-20.

Dieks, Dennis (ed.), The Ontology of Spacetime, Amsterdam: Elsevier (2006).

Dorato, Mauro, "The irrelevance of the presentist/eternalist debate for the ontology of Minkowski spacetime", in Dieks (2006), 93-109.

Hestevold, H Scott and Carter, William R, "On presentism, endurance, and change", Canadian Journal of Philosophy 32 (2002): 491-510.

Klatzky, Roberta L, "Allocentric and egocentric spatial representations: Definitions, distinctions, and interconnections", Lecture Notes in Artificial Intelligence 1404 (1998): 1-17.

Lewis, David, On the Plurality of Worlds, Oxford: Basil Blackwell (1986).

Lombard, Lawrence B, "On the alleged incompatibility of presentism and temporal parts", Philosophia 27 (1999): 253-260.

Meyer, Ulrich, "The presentist's dilemma", Philosophical Studies 122 (2005): 213-225.

Savitt, Steven F, "Presentism and eternalism in perspective", in Dieks (2006), 111-127.

Sider, Theodore, "Quantifiers and temporal ontology", Mind 115 (2006): 75-97.

Wüthrich, Christian, "No presentism in quantum gravity", to be published in Vesselin Petkov (ed.), Space, Time, and Spacetime: Physical and Philosophical Implications of Minkowski's Unification of Space and Time, Springer (forthcoming). 